\title{
Biochemical Features of Type 2 Diabetics in Kushtia District, Bangladesh.
}

\author{
Hasan Mahfuz Reza*1, Md. Rezaul Karim², Md. Abdus Samad ${ }^{3}$
}

\begin{abstract}
Introduction: Biochemical analysis or laboratory tests assist to determine what happening to the body internally. The aim of the present study was to access the biochemical features of type 2 diabetic patients in Kushtia district, Bangladesh. Materials and Methods: The cross-sectional study was conducted in type 2 diabetes mellitus patients who presented to the OPD in three referral diabetic centers in Kushtia district, Bangladesh from August 2016 to July 2017. A total of 282 patients were included in the study. The collected data were checked, entered and analyzed using the computer program Statistical Package for Social Sciences (SPSS) version 22. Results: Biochemical study showed that mean blood hemoglobin level was $12.49 \pm 1.47 \mathrm{~g} / \mathrm{dl}$, mean fasting blood glucose level of the patients was $8.86 \pm 1.67 \mathrm{mmol} / \mathrm{L}$ and blood glucose level two hours after breakfast was $13.94 \pm 2.88 \mathrm{mmol} / \mathrm{L}$. The study showed that the patient having abnormal level of triglyceride (66\%) were higher than normal level (34\%). Conclusion: The subjects had higher triglyceride and LDL values (65.6\% and $28.7 \%$ respectively). These higher percentages with abnormal lipid profile are likely to be more prone to cardiovascular diseases.
\end{abstract}

Keywords: Diabetes mellitus, Type 2 diabetes, Biochemical indices, Lipid profile.

Number of Tables: 03; Number of Figure: 01; Number of References: 21; Number of Correspondence: 04.

*1. Corresponding Author:Dr. Hasan Mahfuz Reza Medical Officer

Urban Primary Health Care Services Delivery Project II

Kushtia Municipality, Kushtia.

Email: hasanreza971@gmail.com

Mobile: 01768956863

2. Dr. Md. Rezaul Karim

Professor

Department of Applied Nutrition and Food Technology Islamic University, Kushtia.

3. Dr. Md. Abdus Samad

Professor

Department of Applied Nutrition and Food Technology

Islamic University, Kushtia.

\section{Introduction:}

Diabetes Mellitus (DM) is a serious health hazard all over the world. In the South East Asian region there were 72 million adults with DM in 2013 and it is expected to rise to more than 123 million by $2035^{1}$. Diabetes mellitus is a chronic condition that arises when the pancreas fails to produce enough insulin or when the body cannot use the insulin produced effectively ${ }^{2}$. It is an increasing threat to the world's health service. Formerly described as a "disease of affluence", it has now become evident that, owing to demographic changes, cultural transition and population ageing, diabetes is now also a "developing countries problem" 3 .
Type 2 diabetes accounts for more than 90\% cases and is associated with older age and obesity ${ }^{4}$. It usually begins as insulin resistance, a disorder in which the cells do not use insulin properly. As the need for insulin rises, the pancreas gradually loses its ability to produce $i^{5}$. The resulting hyperinsulinemia helps maintain normal glucose tolerance. In many individuals, this condition corresponds to the metabolic syndrome of insulin resistance which is defined by obesity, insulin resistance, hyperlipidemia, hyperinsulinemia and hypertension, and do not progress to diabetes always ${ }^{6}$. During the progression of the disease, beta cell function declines and the patient then has a fasting hyperglycemia. It occurs mostly after 40 years in

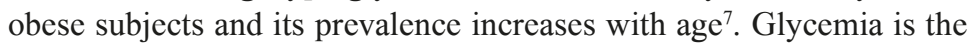
concentration of glucose circulating in the blood. The glucose in the blood from two sources: an exogenous origin (food provides carbohydrates such as sugar, starches, fruits, which are degraded by enzymes, mainly glucose) and endogenous origin since the liver is an organ producing glucose through two pathways, glycogenolysis and gluconeogenesis ${ }^{8}$. Increased rates of hepatic glucose production result in the development of overt hyperglycaemia, especially fasting hyperglycaemia, in patients with type 2 diabetes $^{9}$. In such conditions, lipolysis in adipose tissue is promoted leading to elevated circulating levels of free fatty acids ${ }^{10}$. In addition, kinetics of whole-body protein metabolism are elevated, and net balance is diminished in type 2 diabetes, independently of obesity $^{11}$.

Type 2 diabetes is a disease associated with abnormal carbohydrate metabolism which arises due to insulin deficiency as insulin is the key hormone responsible for glucose homeostasis in blood ${ }^{12}$. Consequently, elevation of blood glucose predominantly affects $\mathrm{RBC}^{6} \mathrm{~s}$, vascular endothelial cells and walls of capillaries which often leads to microvascular complications in T2DM including retinopathy, 
nephropathy and neuropathy ${ }^{13}$. Hyperglycaemia can lead to vascular complications through various mechanisms ${ }^{14}$.

Deformability of RBC's is one of the haemorheological parameters which is altered in type 2 diabetic patients. RBCs of type 2 diabetic patients tend to aggregate more easily when compared with healthy subjects. Excessive aggregation of $\mathrm{RBC}$ is one of the most important features in type 2 diabetic patients with poor glycaemic control. This has a direct effect on the $\mathrm{WBV}^{15}$.

A significant percentage of type 2 diabetic patients have abnormal serum lipid. Recent studies have revealed that insulin resistance is not only associated with hyperglycaemia alone, but also with several other disorders which are associated with the concentrations of lipoproteins ${ }^{16}$. In type 2 diabetic patients, typical abnormalities frequently observed in lipid profile are elevated total and VLDL cholesterol, triglyceride, low levels of HDL, and a large number of dense LDL particles ${ }^{17}$. It is well understood that diabetic dyslipidemia is a major hallmark of metabolic syndrome and found to play an extensive role in the pathogenesis of $\mathrm{CVD}^{18}$. Creatinine is a protein and its assay in blood and urine can evaluate renal function. If the rate is high, it means that renal function is disturbed ${ }^{19}$.

\section{Materials and Methods:}

A descriptive, cross-sectional study was conducted from August 2016 to July 2017 among 282 (male were 144, female were 138,142 resided in urban area and 140 resided in rural area) type 2 diabetic patients attending OPD in three referral diabetic centers in Kushtia district, Bangladesh. After arriving in the center the participants were asked about their fasting status by field volunteers. The investigation was carried out only after reporting of fasting state by the participants. Subjects were asked to sit on a chair and an appropriate blood was taken from the patients. Data were summarized in mean $\pm \mathrm{SD}$, frequency $\&$ percentage and presented in tables using Statistical Package for Social Science (SPSS) version 22. For all analyses, p value $<0.05$ was considered statistically significant.

\section{Results:}

The mean blood hemoglobin level was $12.49 \pm 1.47 \mathrm{~g} / \mathrm{dl}$, in which male hemoglobin level was $12.85 \pm 1.48 \mathrm{~g} / \mathrm{dl}$ and of female was $12.11 \pm 1.36 \mathrm{~g} / \mathrm{dl}$. The mean fasting blood glucose level of the patients was $8.86 \pm 1.67 \mathrm{mmol} / \mathrm{L}$ and blood glucose level two hours after breakfast was $13.94 \pm 2.88 \mathrm{mmol} / \mathrm{L}$. The mean serum creatinine level of the male patients were $1.17 \pm 1.05 \mathrm{mg} / \mathrm{dl}$ and female were $1.26 \pm 1.05 \mathrm{mg} / \mathrm{dl}$. The patients mean total cholesterol, low density lipoprotein; high density lipoprotein and triglyceride levels were $197.23 \pm 48.99 \mathrm{mg} / \mathrm{dl}, 117.21 \pm$ $44.65 \mathrm{mg} / \mathrm{dl}, 34.96 \pm 5.38 \mathrm{mg} / \mathrm{dl}$ and $225.30 \pm 74.08 \mathrm{mg} / \mathrm{dl}$ respectively (Table-I).
Table-I: Mean biochemical indices of the respondents (Diabetic Patients).

\begin{tabular}{lccccc}
\hline Biochemical indices & Male & Female & $\begin{array}{c}\text { Male \& female } \\
\text { Combined }\end{array}$ & $\begin{array}{c}\text { P- } \\
\text { value }\end{array}$ & $\begin{array}{c}\text { Normal } \\
\text { Range }\end{array}$ \\
\hline $\begin{array}{l}\text { Blood hemoglobin } \\
\text { level (g/dl) }\end{array}$ & $12.85 \pm 1.48$ & $12.11 \pm 1.36$ & $12.49 \pm 1.47$ & .000 & M: 14-18,F: 11.5-16.5 \\
$\begin{array}{l}\text { Fasting blood } \\
\text { glucose (mmol/L) }\end{array}$ & $8.69 \pm 1.48$ & $9.04 \pm 1.84$ & $8.86 \pm 1.67$ & .080 & $<7.0$ \\
$\begin{array}{l}\text { Bl. Glucose 2 hours } \\
\text { after breakfast }\end{array}$ & $13.86 \pm 2.92$ & $14.01 \pm 2.84$ & $13.94 \pm 2.88$ & .673 & $<11.1$ \\
$\begin{array}{l}\text { Serum creatinin } \\
\text { (mg/dl) }\end{array}$ & $1.17 \pm 1.05$ & $1.26 \pm 1.05$ & $1.22 \pm 1.05$ & .480 & $0.70-1.20$ \\
$\begin{array}{l}\text { Total cholesterol } \\
\text { (mg/dl) }\end{array}$ & $198.49 \pm 51.87$ & $195.92 \pm 45.96$ & $197.23 \pm 48.99 .660$ & Up to 200 \\
LDL (mg/dl) & $119.66 \pm 48.34$ & $114.65 \pm 40.45$ & $117.21 \pm 44.65 .347$ & $<150$ \\
HDL (mg/dl) & $35.31 \pm 5.53$ & $34.59 \pm 5.21$ & $34.96 \pm 5.38$ & .263 & M: $>45$, F: $>35$ \\
Triglycerides (mg/dl) & $217.57 \pm 70.95$ & $233.37 \pm 76.63$ & $225.30 \pm 74.08 .073$ & $50-150$ \\
\hline $\begin{array}{l}\text { HDL }=\text { High density lipoprotein } \\
\text { LDL }=\quad \text { Low density lipoprotein }\end{array}$ & & & & \\
\end{tabular}

The mean fasting blood glucose levels for female in rural area was $9.16 \pm 2.03$ and urban area was $8.93 \pm 1.65$. Mean two hours after blood glucose levels for male in rural area was $14.36 \pm 2.92$ and urban area was $13.32 \pm 2.83$. Mean blood hemoglobin levels for male and female living in rural area were $12.75 \pm 1.49$ and $11.98 \pm 1.36$ (Table-II).

Table-II: Mean biochemical indices of the respondents (Diabetic Patients) in correlation to place of residence.

\begin{tabular}{cccc}
\hline Biochemical indices: & Male & Female & $\begin{array}{c}\text { Male \& Female } \\
\text { Combined }\end{array}$ \\
\hline Blood hemoglobin level $(\mathrm{g} / \mathrm{dl})$ & $12.95 \pm 1.48$ & $12.23 \pm 1.36$ & $12.58 \pm 1.46$ \\
Urban & $12.75 \pm 1.49$ & $11.98 \pm 1.36$ & $12.39 \pm 1.48$ \\
Rural & & & \\
Fasting blood glucose (mmol/L) & $8.57 \pm 1.43$ & $8.93 \pm 1.65$ & $8.76 \pm 1.55$ \\
Urban & $8.79 \pm 1.52$ & $9.16 \pm 2.03$ & $8.96 \pm 1.78$ \\
Rural & & & \\
Bl. Glucose 2 hours after breakfast & $13.32 \pm 2.83$ & $13.92 \pm 2.81$ & $13.63 \pm 2.82$ \\
Urban & $14.36 \pm 2.92$ & $14.11 \pm 2.90$ & $14.25 \pm 2.90$ \\
Rural & & & \\
Serum creatinin (mg/dl) & $1.34 \pm 1.25$ & $1.23 \pm 1.07$ & $1.28 \pm 1.16$ \\
Urban & $1.01 \pm 0.79$ & $1.29 \pm 1.03$ & $1.14 \pm 0.92$ \\
Rural &
\end{tabular}

The distribution of patients with normal and abnormal levels of various lipid constituents differed. Majority of the patients $65.6 \%$ had abnormal levels of triglyceride followed by $31.2 \%$ with abnormal total cholesterol, $28.7 \%$ with abnormal LDL and $40.8 \%$ with abnormal HDL (Table-III).

Table-III: Lipid profile of the respondents (Diabetic Patients).

\begin{tabular}{lccccccc}
\hline Lipids categories & \multicolumn{2}{c}{ Normal } & \multicolumn{2}{c}{ Abnormal } & \multicolumn{2}{c}{ Total } & Normal values \\
\hline \multirow{2}{*}{ Total cholesterol } & $(\mathrm{n})$ & $(\%)$ & $(\mathrm{n})$ & $(\%)$ & $(\mathrm{n})$ & $(\%)$ & $(\mathrm{mg} / \mathrm{dl})$ \\
$\quad 194$ & 68.8 & 88 & 31.2 & 282 & 100.0 & Up to 200 \\
LDL & 201 & 71.3 & 81 & 28.7 & 282 & 100.0 & $<150$ \\
HDL & 167 & 59.2 & 115 & 40.8 & 282 & 100.0 & $\mathrm{M}>45, \mathrm{~F}>35$ \\
Triglycerides & 97 & 34.4 & 185 & 65.6 & 282 & 100.0 & $50-150$ \\
\hline
\end{tabular}

According to Figure 1, the patient having abnormal level of triglyceride $(66 \%)$ were higher than normal level (34\%). 


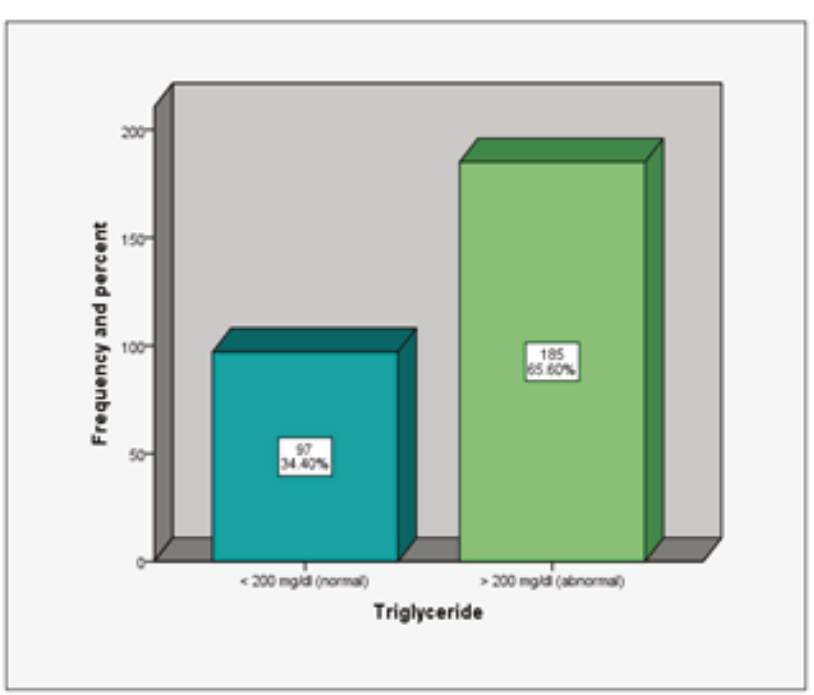

Figure-1: Showing distribution of normal and abnormal triglyceride level of the diabetics.

\section{Discussion:}

This study showed that mean fasting blood glucose levels for female in rural area was $9.16 \pm 2.03$ and urban area was $8.93 \pm 1.65$. So, the mean fasting blood glucose levels for females showed a fairly different values compared to mean following fasting blood glucose in our urban and rural population. Mean two hours after blood glucose levels for male in rural area was $14.36 \pm 2.92$ and urban area was $13.32 \pm 2.83$. Here, the mean two hours after blood glucose levels for males showed fairly different values compared to mean following two hours after blood glucose in our urban and rural population.

Study showed that the respondents had abnormal triglyceride in high percentage $(65.6 \%)^{20}$. The mean values for lipid profile of the study were total cholesterol $197.23 \pm 48.99 \mathrm{mg} / \mathrm{dl}$, low density lipoprotein $117.21 \pm$ $44.65 \mathrm{mg} / \mathrm{dl}$, high density lipoprotein $34.96 \pm 5.38 \mathrm{mg} / \mathrm{dl}$ and triglyceride $225.30 \pm 74.08 \mathrm{mg} / \mathrm{dl}$. Dyslipidemia does exist in diabetes mellitus and they are always at risk of macro-vascular complications. The abnormalities of lipid profile in diabetics include elevated total cholesterol, triglyceride, low density lipoprotein (LDL) and reduced high density lipoprotein (HDL) ${ }^{21}$.

Conclusion:

Diabetes mellitus is a major public health problem that requires proper medical and dietary management. The subjects had higher triglyceride and LDL values (65.6\% and $28.7 \%$ respectively). These higher percentages with abnormal lipid profile are likely to be more prone to cardiovascular diseases. The high intake of fruit and vegetables among the diabetics could be because of high level of awareness on the importance of fruits and vegetables to diabetes management as vegetables contain fiber, which helps reducing cholesterol thereby controlling blood glucose. Diabetes patients should be counseled to adopt healthy eating habits and encouraged them to improve their diets in order to prevent diabetes and its complications.

Conflict of Interest: None.

Acknowledgement:

The authors are grateful to the secretary ethical committee of each of the three diabetic centers to use patients from out-patient departments.

\section{References:}

1. Online atlas of International diabetes federation: 6th edition. 2013.

https://www.idf.org/sites/default/files/EN_6E_Atlas_Full_0.pdf.

2. Alva M."Diabetes and lifestyle in the New Millennium. World Diabetes day presentation." 2000.

3. King H, Rewers M. Diabetes in adults is now a third world problem, Bulletin of the World Health Organization. 1991; 69(6): 643-648.

4. Olefsky JM. Prospects for research in diabetes mellitus. The Journal of American Medical Association. 2001; 285: 628-632.

https://doi.org/10.1001/jama.285.5.628

PMid:11176871

5. Cohen $P$. The 20th century struggle to decipher insulin signaling. Nat Rev Mol Cell Biol. 2006; 7: 867-873.

https://doi.org/10.1038/nrm2043

PMid:17057754

6. Ford ES. The metabolic syndrome and mortality from cardiovascular disease and ail-causes: findings from the National Health and Nutrition Examination Survey Il Mortality Study. Atheroscierosis. 2004; 173:309-14.

7. Defronzo RA. Insulin resistance: a multifaced syndrome responsible, obesity, hypertension, dyslipidaemia and atherosclerosis. Neth. J. Med. 1997 ; 50:191-7.

8. Wens J, Van Casteren V, Vemieire E. Diagnosis and treatment of type 2 diabetes in three Belgian regions. Registration via a network of sentines general practices. Eur J Epidemiol. 2001;17:743-50.

9. DeFronzo RA, Bonadonna RC, Ferannini E. Pathogenesis of NIDDM. A balanced overview. Diab Care. 1992; 15: 318-368.

https://doi.org/10.2337/diacare.15.3.318

PMid:1532777

10. Botion LM, Green A. Long-term regulation of lipolysis and hormonesensitive lipase by insulin and glucose. Diabetes. 1999; 48: 1691-1697.

https://doi.org/10.2337/diabetes.48.9.1691

PMid:10480596 
11. Gougeon R, Morais JA, Chevalier S, Pereira S, Lamarche M, Marliss EB. Determinants of whole-body protein metabolism in subjects with and without type 2 diabetes. Diabetes Care. 2008; 31: 128-133.

https://doi.org/10.2337/dc07-1268

PMid:17921356

12. Kumar PJ \& Clark M. Diabetes Mellitus and other disorders of metabolism. Kumar \& Clark Clinical Medicine. 2005: 1101-1130.

13. Pirat J C. Diabetes mellitus and its degenerative complications - A prospective study of 4.400 patients observed between 1947 and 1973. Diabetes Care. 1978; 1: 168-188.

https://doi.org/10.2337/diacare.1.3.168

14. DSouza A, Hussain M, Howarth F, Woods N, Bidasee K, \& Singh J. Pathogenesis and pathophysiology of accelerated atherosclerosis in the diabetic heart. Molecular and Cellular Biochemistry. 2009; 331: 89-116.

https://doi.org/10.1007/s11010-009-0148-8

PMid:19466528

15. Grigoleit H G, Lehrach F, \& Muller R. Diabetic angiopathy and blood viscosity. Acta Diabet Lat. 1973; 10 : 1311-1324.

https://doi.org/10.1007/BF02590717

PMid:4793677

16. Grundy SM. Small LDL, Atherogenic Dyslipidemia, and the Metabolic Syndrome. Circulation. 1997; 95: 1-4.

https://doi.org/10.1161/01.CIR.95.1.1

PMid:8994405
17. Lamarche B, Tchernof A, Moorjani S, Cantin B, Dagenais GR, Lupien PJ, et al. Small, Dense Low-Density Lipoprotein Particles as a Predictor of the Risk of Ischemic Heart Disease in Men. Circulation. 1997; 95: 69-75.

https://doi.org/10.1161/01.CIR.95.1.69

\section{PMid:8994419}

18. Wannamethee SG, Lowe GDO, Rumley A, Cherry L, Whincup PH, \& Sattar N. Adipokines and Risk of Type 2 Diabetes in Older Men. Diabetes Care. 2007; 30: 1200-1205.

https://doi.org/10.2337/dc06-2416

PMid:17322479

19. Fabiny DL, Ertingshausen G. Automated reaction-rate method for determination of serum creatinine with centriChem. Clin Chem. 1971; 17:696-700.

20. Betteridge J. D. Risk factors for arterial disease in diabetes: dyslipidemia. Diabetes Agiopathy.1999; 6: 66 87.

21. Bello-Sani F., Anumah FEO. Dyslipidemia among persons with type 2 diabetes mellitus in Ahmadu Bello University Teaching Hospital, Kaduna (ABUTH) Nigerian society of Endocrinology and Metabolism. NSEM Conference proceedings.2006: 10. 